\title{
Transient Suppression of Clonal Hemopoiesis Associated with Pregnancy in a Patient with a Myeloproliferative Disorder
}

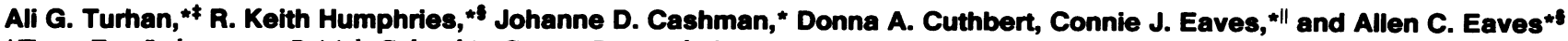 \\ *Terry Fox Laboratory, British Columbia Cancer Research Centre, Vancouver, British Columbia V5Z1L3, Canada; and the \\ Departments of ${ }^{\ddagger}$ Pathology, ${ }^{8}$ Medicine, and "Medical Genetics, University of British Columbia, Vancouver, British Columbia V6T1W5, \\ Canada
}

\begin{abstract}
We have used restriction fragment length polymorphism analysis to study the clonal involvement of the blood cells in a woman with myeloproliferative disease, whose initially high platelet count $(940,000 / \mu l)$ spontaneously decreased during a normal pregnancy but then returned rapidly to the same high level after delivery of her child. Analysis of her erythroid progenitors showed the presence of erythropoietin-independent progenitors before, during, and after her pregnancy, consistent with a diagnosis of myeloproliferative disease, and persistence of the abnormal clone throughout the period of study. Analysis of DNA from her blood granulocytes showed these to be polyclonal at mid-pregnancy, when her platelet count had decreased to normal values, in comparison to the monoclonal pattern exhibited by her blood granulocytes 3 mo postpartum, when her platelet count was again elevated. These results demonstrate a partial conversion to normal, polyclonal hemopoiesis during her pregnancy and suggest a previously unanticipated differential sensitivity of normal and neoplastic hemopoietic cells to physiological changes associated with this state.
\end{abstract}

\section{Introduction}

Studies of congenital mosaics have allowed the identification of disease states characterized by the overgrowth of a single clone of cells in tissues that are normally polyclonal. Although a number of genetic markers have been exploited for such studies, the most frequently used are allelic differences located on the X-chromosome. Because of lyonization early in embryogenesis, all females heterozygous at such loci represent natural mosaics. The glucose-6-phosphate dehydrogenase $(\mathrm{G} 6 \mathrm{PD})^{1}$ isoenzyme system is an example of a gene that has

Address reprint requests to Dr. Ali G. Turhan, Terry Fox Laboratory, Cancer Research Centre, 601 West 10th Avenue, Vancouver, British Columbia V5Z 1 L3 Canada.

Received for publication 4 December 1987 and in revised form 2 March 1988.

1. Abbreviations used in this paper: $\mathrm{CML}$, chronic myelogenous leukemia; Ep, erythropoietin; ET, essential thrombocytosis; G6PD, glucose-6-phosphate dehydrogenase; HPRT, hypoxanthine phosphoribosyl transferase; PV, polycythemia vera; WBC, white blood cells.

J. Clin. Invest.

(c) The American Society for Clinical Investigation, Inc.

0021-9738/88/06/1999/05 $\$ 2.00$

Volume 81, June 1988, 1999-2003 been used extensively to demonstrate clonal blood cell populations in patients with various myeloproliferative disorders. In all cases of G6PD heterozygotes with chronic myelogenous leukemia (CML), polycythemia vera (PV), or essential thrombocytosis (ET) that have been examined to date, origin of the neoplastic clone in a pluripotent hemopoietic stem cell has been demonstrated (1). Moreover, $>95 \%$ of the mature red cells, granulocytes, and platelets in these individuals have consistently been found to be a part of the neoplastic clone, even though the presence of more primitive, normal, hemopoietic progenitors can frequently be demonstrated (2-4). Chemotherapeutic control of the myeloproliferative diseases usually results in the alleviation of symptoms and return of the blood count to normal values. Nevertheless, the clone typically remains dominant in the peripheral blood and reversal of the suppression of coexisting normal progenitors in the marrow is difficult to achieve. The mechanisms underlying this differential proliferative activity of normal and neoplastic progenitors in vivo are completely unknown, although the fact that normal progenitor proliferation is more favorably supported in vitro (2-4) suggests that physiological factors may play a role.

We recently had the opportunity to study a female patient with a myeloproliferative disorder, in whom a transient clinical remission occurred spontaneously during pregnancy. The assessment of the clonal status of her circulating granulocytes was possible by virtue of heterozygosity for a Bam $\mathrm{H} 1$ site in her X-linked hypoxanthine phosphoribosyl transferase (HPRT) genes (5). In addition, in vitro colony assays with and without added erythropoietin (Ep) and $\left[{ }^{3} \mathrm{H}\right]$ thymidine suicide measurements were used to assess the presence of neoplastic progenitors in her blood and marrow.

\section{Methods}

Case report. A 32-yr-old woman was seen by her physician in October 1985 for nonspecific bowel symptoms. The white cell count (WBC) was $11,600 / \mu \mathrm{l}$; the hemoglobin $(\mathrm{Hb}), 14.4 \mathrm{~g} / 100 \mathrm{ml}$; and the platelet count, $940,000 / \mu \mathrm{l}$. The peripheral blood smear showed occasional giant platelets. The bone marrow aspirate biopsy was consistent with a diagnosis of myeloproliferative disease, possibly ET. The leukocyte alkaline phosphatase score was normal, as was the karyotype of all 27 marrow metaphases examined. The red cell mass was slightly elevated at $30 \mathrm{ml} / \mathrm{kg}$ of body weight. Although not clinically palpable, the spleen was enlarged on nuclear scan. The patient received no treatment and remained asymptomatic apart from her colonic dysmobility. 7 mo later, she became pregnant. At that time, her $\mathrm{Hb}$ was $13.1 \mathrm{~g} / 100$ $\mathrm{ml}$, her WBC was $12,200 / \mu \mathrm{l}$, and her platelet count was $678,000 / \mu \mathrm{l}$. Subsequent blood counts showed a steady decrease of her platelet counts to $292,000 / \mu$ in February 1987. At the end of January 1987, she gave birth to a normal child. Within weeks after the delivery, her 


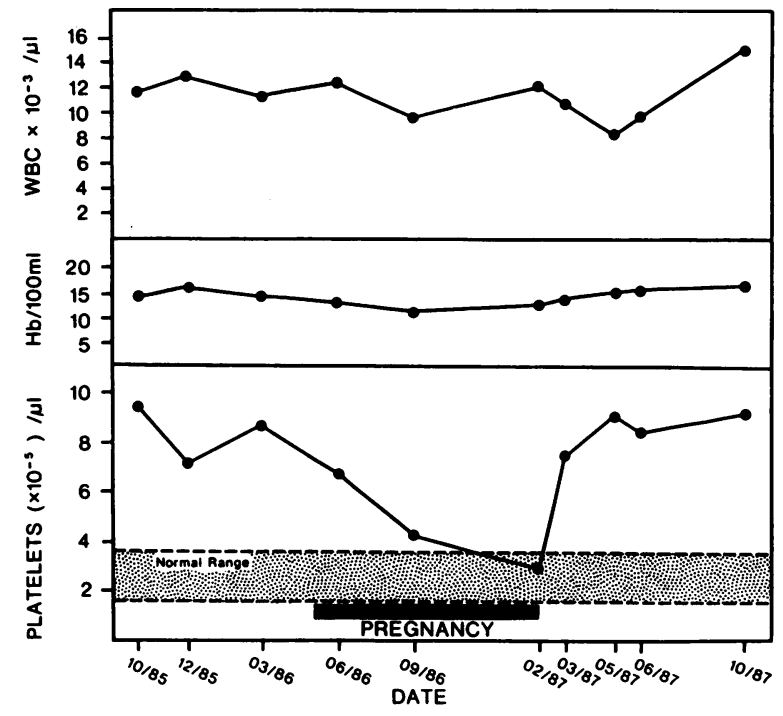

Figure 1. Changes in the peripheral blood counts of the patient studied from the time of her diagnosis.

platelet count rose to $723,000 / \mu$ l. In May 1987 , the $\mathrm{Hb}$ was $15.1 \mathrm{~g} / 100$ $\mathrm{ml}$, the WBC was $8,400 / \mu \mathrm{l}$, and the platelet count, $903,000 / \mu \mathrm{l}$. She remained asymptomatic and had not been treated with any chemotherapy as of October 1987. The changes in her peripheral blood counts between October 1985 and October 1987 are shown in Fig. 1.

Methylcellulose assays. Marrow buffy coat and light-density $\left(<1.077 \mathrm{~g} / \mathrm{mm}^{3}\right)$ PBMC fractions were isolated by standard procedures from heparinized samples, washed, diluted, and suspended in methylcellulose cultures containing $30 \% \mathrm{FCS}, 1 \%$ deionized BSA, $10^{-4}$ M 2-mercaptoethanol, and $10 \%$ human leukocyte-conditioned medium (6). Cultures to which Ep (7) was added contained a final Ep concentration of $3 \mathrm{U} / \mathrm{ml}$. Cultures to which no Ep was added contained $<0.002 \mathrm{U} / \mathrm{ml}$ of $\mathrm{Ep}(8)$. Cells were plated in $35-\mathrm{mm}$ petri dishes at a final concentration of $2 \times 10^{5}$ marrow cells and $4 \times 10^{5}$ blood mononuclear cells per $1.1-\mathrm{ml}$ culture. Small erythroid colonies were scored 10-12 d later and large erythroid colonies, granulopoietic colonies, and occasional mixed colonies containing both granulopoietic and erythroid elements were scored after 18-21 d according to standard criteria (6-8).

$\left[{ }^{3} \mathrm{H}\right]$ Thymidine suicide measurements. Marrow or blood cells prepared for plating were washed in nucleoside-free Hepes buffered medium, preincubated for $1 \mathrm{~h}$ at $37^{\circ} \mathrm{C}$ in nucleoside-free medium without serum and then exposed for $20 \mathrm{~min}$ to $20 \mu \mathrm{Ci} / \mathrm{ml}$ of high specific activity $\left[{ }^{3} \mathrm{H}\right]$ thymidine $(25 \mathrm{Ci} / \mathrm{mmol})$ in a small volume at $37^{\circ} \mathrm{C}$ and pH 7.2 as previously described (9). Excess cold thymidine was then added and the cells washed and plated. A control aliquot was also always incubated in the same nucleoside-free medium without the addition of tritiated thymidine and then plated in the same way. Clonogenic cells in $\mathrm{S}$ phase during the 20 min of incubation with $\left[{ }^{3} \mathrm{H}\right]$ thymidine take up and incorporate a lethal dose of the nucleoside, resulting in their subsequent failure to form colonies. This suicide effect is represented as percent kill $=$ (control count $-\left[{ }^{3} \mathrm{H}\right]$ thymidine count/ control count) $\times 100 \%$. Because approximately half of the cells in a totally cycling population will be in $\mathrm{S}$ phase at any given time, a percent kill of $>10 \%$ is usually indicative of a significant cycling component in the population. To ensure that an adequate number of colonies of each progenitor category of interest was available for derivations of percent kill values, six replicate $1.1-\mathrm{ml}$ cultures were set up from each treatment group.

DNA hybridization studies. Granulocytes were isolated by $\mathrm{NH}_{4} \mathrm{Cl}$ lysis of the copelleted red cells obtained after centrifugation of the peripheral blood sample on Ficoll-Hypaque $(1.077 \mathrm{~g} / \mathrm{ml})$ to separate the light-density mononuclear cell fraction. This method routinely gives highly purified preparations containing $>95 \%$ granulocytes. Bone marrow fibroblasts were obtained by seeding marrow cells at $\sim 2$ $\times 10^{6}$ cells $/ \mathrm{ml}$ in $\alpha$-medium plus $20 \%$ FCS and subculturing the fibroblasts as they became confluent at 2-3 wk intervals for several passages. High molecular weight DNA was then obtained from granulocytes and bone marrow fibroblasts using SDS-proteinase $\mathrm{K}$ digestion followed by phenol-chloroform extractions. 8-15 $\mu \mathrm{g}$ of DNA was digested with Bam H1 using $10 \mathrm{U} / \mu \mathrm{g}$ of DNA for $1.5-2 \mathrm{~h}$ in the buffer recommended by the manufacturer (Bethesda Research Laboratories, Gaithersburg, MD). After ethanol precipitation, the pellet was dissolved in $300 \mu \mathrm{l}$ of Tris-EDTA buffer ( $3 \mathrm{mM}$ Tris and $0.2 \mathrm{mM}$ EDTA, $\mathrm{pH}$ 7.5). This volume was then divided in two aliquots of $150 \mu \mathrm{l}$ each. One aliquot was left undigested. The other was further digested with fivefold excess of Hpa II for 2-4 h. Both samples were then electrophoresed on a $1 \%$ agarose gel and blotted onto a nylon membrane (ZetaProbe; Bio-Rad Laboratories, Mississauga, Ontario, Canada) using alkaline transfer (10). Prehybridization of the membranes was performed at $60^{\circ} \mathrm{C}$ in a $20 \mathrm{ml}$ of a buffer containing $0.9 \mathrm{M} \mathrm{NaCl}, 10 \%$ formamide, $1 \%$ SDS, 2 mM EDTA, $1 \%$ nonfat dried milk, and 0.5 $\mathrm{mg} / \mathrm{ml}$ denaturated salmon sperm DNA. Hybridization conditions were the same except for the inclusion of dextran sulfate (Sigma Chemical Co., St. Louis, MO) at a concentration of 10\%. The HPRT p600 probe is a $600-b p$ Hpa II subfragment of the pPB1.7 human HPRT probe cloned into the Acc I site of pGEM-4 (11). The 600-bp insert was isolated from agarose gels and ${ }^{32} \mathrm{P}$-labeled to high specific activity by the multiprime labeling method (12). After hybridization for $18-20 \mathrm{~h}$, filters were washed at $60^{\circ} \mathrm{C}$ in $0.1 \%$ SDS and $0.1 \%$ saline sodium citrate (SSC) with four changes. Autoradiography was performed at $-70^{\circ} \mathrm{C}$ using a Kodak XAR-5 film for $13-72 \mathrm{~h}$. Densitometric scanning was performed on the films using a Hoefer scanning densitometer (Hoefer Scientific Instruments, San Francisco, CA).

\section{Results}

Fig. 1 shows the time course of changes in the patient's peripheral blood counts during the 2-yr period of study starting with her initial diagnosis in October 1985. The temporal association between the start and end of her 9-mo pregnancy and a corresponding decline and resurgent rise in the platelet count is clearly evident. Because she received no treatment during the entire period, the change in her platelet counts is most likely related to physiologic parameters associated with her pregnancy, which was otherwise unremarkable and ended with a spontaneous delivery of a normal child.

Two bone marrow samples and four peripheral blood samples were obtained for assessment of clonogenic progenitor numbers and Ep-dependence. Results are summarized in Table I. At no time did there appear to be a significant increase in the concentration of any erythroid progenitor type assessed, although her circulating granulopoietic progenitors were consistently at the high extreme of the normal range. On every occasion, however, some readily scored Ep-independent erythroid colony-forming units (CFU-E) and erythroid burstforming units (BFU-E) were detected. Of particular note was the detection of Ep-independent CFU-E and BFU-E in her September 1986 blood sample, which was obtained in the middle of her pregnancy at a time when her platelet count had spontaneously decreased to $426,000 / \mu$ l.

Table II summarizes the results of $\left[{ }^{3} \mathrm{H}\right]$ thymidine suicide studies performed on peripheral blood and marrow progenitors obtained 3 and 4 mo postpartum, respectively, at a time when her platelet count had again risen to $>800,000 / \mu 1$. The data shown in Table II are limited to those progenitor categories that in normal individuals appear quiescent. In every instance there was an abnormal increase in progenitor cycling in 
Table I. Assessment of the Total and Ep-Independent Progenitor Concentrations in Blood and Marrow Samples Obtained before, during, and after Pregnancy*

\begin{tabular}{|c|c|c|c|c|c|c|c|c|}
\hline \multirow[b]{2}{*}{ Date } & \multirow{2}{*}{$\begin{array}{l}\text { Status relative to } \\
\text { period of pregnancy }\end{array}$} & \multirow{2}{*}{$\begin{array}{l}\text { Platelet count } \\
\text { per microliter }\end{array}$} & \multirow[b]{2}{*}{ Specimen } & \multicolumn{2}{|c|}{ CFU-E } & \multicolumn{2}{|c|}{ BFU-E } & \multirow[b]{2}{*}{ CFU-GM } \\
\hline & & & & $+\mathrm{Ep}$ & $-E p(\%$ of $+E p)$ & $+\mathrm{Ep}$ & $-E p(\%$ of $+E p)$ & \\
\hline \multirow[t]{2}{*}{$10 / 1985$} & Before & 940,000 & Blood & 88 & $19(22 \%)$ & 490 & $49(10 \%)$ & 228 \\
\hline & & & Marrow & 69 & $46(67 \%)$ & 96 & $28(29 \%)$ & 87 \\
\hline $09 / 1986$ & During & 426,000 & Blood & 89 & $188(100 \%)$ & 648 & $201(31 \%)$ & 347 \\
\hline $05 / 1987$ & After & 903,000 & Blood & 25 & $14(56 \%)$ & 283 & $141(50 \%)$ & 85 \\
\hline \multirow[t]{2}{*}{$06 / 1987$} & After & 847,000 & Blood & 64 & $13(21 \%)$ & 747 & 97 (13\%) & 352 \\
\hline & & & Marrow & 25 & $8(32 \%)$ & 38 & $6(17 \%)$ & 38 \\
\hline \multirow[t]{2}{*}{ Normal values ${ }^{\ddagger}$} & & & Blood & $1-345$ & 0 & $21-841$ & 0 & $2-290$ \\
\hline & & & Marrow & $19-598$ & 0 & $7-671$ & $\mathbf{0}$ & $13-312$ \\
\hline
\end{tabular}

* Values for blood are expressed on a per milliliter basis. Values for marrow are per $2 \times 10^{5}$ buffy coat cells. ${ }^{\ddagger}$ Normal values show the range defined by \pm 3 SD (13).

the corresponding progenitor cell types obtained from the patient studied here. Other categories of progenitors from this patient, e.g. CFU-E or granulocyte-macrophage CFU (CFUGM) in marrow, which in normal individuals already show a significant rate of turnover with this method, yielded similar, i.e., unchanged suicide values (data not shown).

Southern blot analysis of granulocyte DNA showed heterozygosity for a polymorphic Bam $\mathrm{H} 1$ site in the X-linked HPRT locus of this patient (Fig. $2 A$, lanes 1 and 3). Clonality analysis was therefore possible using the method developed by Vogelstein et al. (5) in which Bam H1 digestion to reveal the two alleles is followed by digestion with the methylation sensitive enzyme, Hpa II, to assess the relative proportion of active alleles. At midpregnancy (September 1986), granulocyte DNA showed an equal sensitivity of the 24- and 12-kb HPRT fragments to Hpa II digestion (lane 2), indicating that the active alleles were equally distributed, as expected from a polyclonal cell population. Similarly, 4 mo postpartum, DNA obtained from fibroblast cultures showed a polyclonal pattern (Fig. $2 B$, lanes 1 and 2). In contrast, analysis of postpregnancy periph-

Table II. Progenitor $\left[{ }^{3}\right.$ H]Thymidine Suicide Values*

\begin{tabular}{|c|c|c|c|}
\hline \multirow[b]{2}{*}{ Specimen } & \multirow[b]{2}{*}{ Progenitor } & \multicolumn{2}{|c|}{ \% Kill ${ }^{*}$} \\
\hline & & Patient & Normals \\
\hline Blood & CFU-E & $49(48 / 95)$ & $1.1 \pm 2.6$ \\
\hline Blood & BFU-E & $42(648 / 1,118)$ & $0 \pm 1.2$ \\
\hline Blood & CFU-GM & $62(171 / 450)$ & $0 \pm 1.9$ \\
\hline Bone marrow & $\begin{array}{c}\text { Primitive BFU-E } \\
\text { (>16 clusters) } \\
\text { (>8 clusters) }\end{array}$ & $\begin{array}{l}36(9 / 14) \\
41(29 / 49)\end{array}$ & $\begin{array}{r}3.6 \pm 1.7 \\
13.6 \pm 2.1\end{array}$ \\
\hline
\end{tabular}

\footnotetext{
* Ascertained 3 (blood) and 4 (marrow) mo postpartum.

₹ Calculated from assays of a total of $2.4 \times 10^{6}$ blood cells, or 1.2 $\times 10^{6}$ marrow cells, plated in six replicate $1.1-\mathrm{ml}$ cultures per treatment group. Values in brackets represent the actual total number of colonies scored in all six dishes with/without $\left[{ }^{3} \mathrm{H}\right]$ thymidine.

$\$$ Values are the mean \pm 1 SEM from nine normal blood donors and for 20 marrow samples obtained either from donors of marrow transplants or from untreated patients undergoing hematologic assessment whose marrows showed no disease involvement.
}

eral blood granulocyte DNA ( 3 mo postpartum) revealed complete disappearance of the 24-kb HPRT band, without a significant change in the intensity of the $12-\mathrm{kb}$ band, indicating a monoclonal cell population (lanes 3 and 4 ). This pattern is analogous to that exhibited by the granulocyte DNA of a female patient with CML who was studied simultaneously as a control using the same approach (lanes 5 and 6 ). The only difference in the pattern shown in this latter case is the persistence of the 24-kb band and disappearance of the 12-kb band after Hpa II digestion indicating the origin of the CML clone in a cell with an active $12-\mathrm{kb}$ allele.

\section{Discussion}

We have presented evidence of a spontaneous, pregnancy-associated hematologic remission of a myeloproliferative disease using a combination of cell culture and molecular biology techniques. The initial clinical presentation was consistent with a diagnosis of ET, although PV could not be excluded according to the criteria of the PV Study Group (14), since the initial bone marrow had no stainable iron and the patient did not receive iron therapy. Methylcellulose assays at presentation showed the presence of Ep-independent BFU-E and CFU-E in both marrow and blood samples (Table I). During the clinical remission of her disease (4 mo postconception), we were able to study the patient using two approaches. First, a repeat hemopoietic colony assay showed the persistence of a neoplastic clone as indicated by the presence of a significant Ep-independent erythroid progenitor population. Secondly, Southern blot analysis revealed the presence of granulocytes of polyclonal derivation (Fig. 2). Her platelet count increased rapidly after the delivery of her child (Fig. 1). 3 and 4 mo later, she continued to have a readily detectable Ep-independent erythroid progenitor population and $\left[{ }^{3} \mathrm{H}\right]$ thymidine suicide measurements showed that progenitor compartments, quiescent in normal individuals, were actively cycling in her case even though she had received no treatment. At the same time, HPRT restriction fragment length polymorphism analysis revealed a typical monoclonal pattern in her granulocytes (Fig. 2).

The study of this patient reinforces previous findings showing that normal progenitor clones persist in patients with myeloproliferative disorders and that they can reemerge when 
a

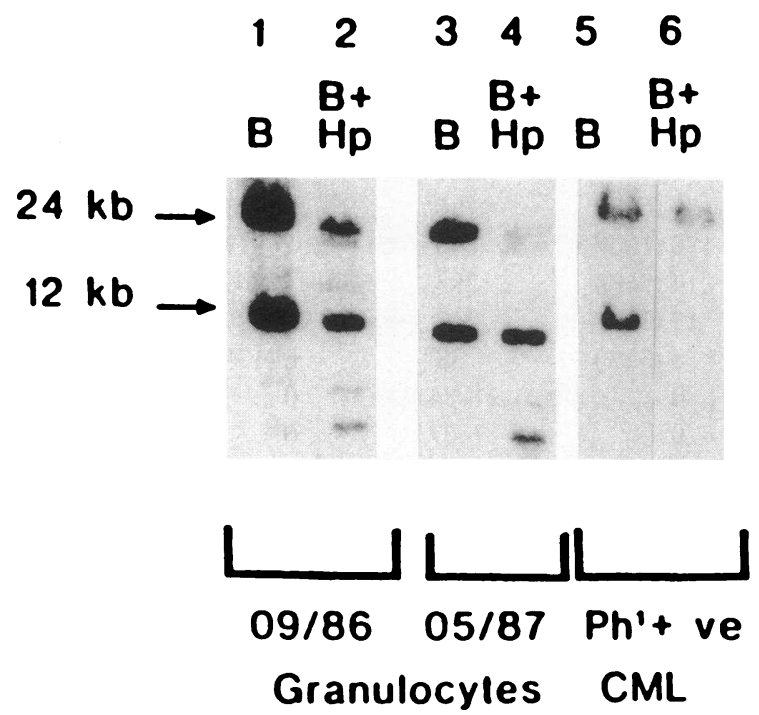

b

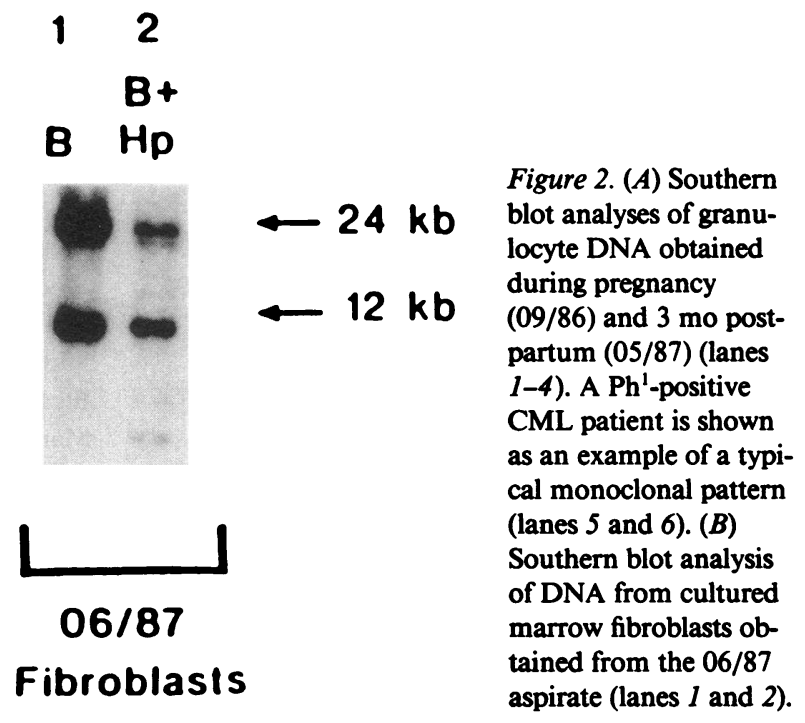

the neoplastic clone is suppressed or inhibited transiently. In PV, the presence of normal progenitors was first documented by studies of two patients who were also G6PD heterozygotes (2). In CML the presence of normal progenitors in fresh blood and marrow samples is more difficult to demonstrate $(4,15$, 16). However, the use of agents that select against $\mathrm{Ph}^{1}$-positive cells either in vivo $(17,18)$ or in vitro in long-term marrow cultures $(3,4)$ has clearly established their presence in a large proportion of CML patients.

Deregulation of the control of primitive neoplastic progenitors has been documented in both PV and CML (reviewed in reference 13). In ET, it is not clearly established whether there is a similar alteration in the cycling characteristics of neoplastic progenitors. In the patient studied here, normally quiescent blood and marrow progenitors were found to be actively cycling at a time when the patient was in relapse and her neoplastic clone was clearly dominant as shown by the monoclonal pattern exhibited by her granulocytes. Because she had not been exposed to any cytotoxic treatment, the increased turnover of her primitive hemopoietic progenitor cells probably reflects the underlying disease process. Her clinical findings, however, make it difficult to distinguish between a diagnosis of ET and PV.

This case illustrates the usefulness of clonality analysis with restriction fragment length polymorphism of X-linked genes (such as HPRT) combined with methylation analysis to demonstrate different stages of clonal progression. Our data show that this technique has sufficient sensitivity to detect normal cells even in the presence of a significant neoplastic clone (as indicated by the presence of a readily detectable Ep-independent erythroid progenitor population). To our knowledge this is the first report documenting a spontaneous, transient remission of a myeloproliferative disease during pregnancy with reactivation of normal hemopoiesis. This strongly suggests a previously unsuspected differential sensitivity of normal and neoplastic progenitors to physiological changes associated with this condition, either hormonal or immunological (19).

\section{Acknowledgments}

The authors are indebted to Dr. B. Vogelstein for providing the HPRT probes used. We are also grateful to $M$. Coulombe for typing the manuscript.

This study was supported by a grant from the National Cancer Institute of Canada and core funds from the British Columbia Cancer Foundation and the Cancer Control Agency of British Columbia. Dr. Turhan is a recipient of a Terry Fox Postdoctoral Fellowship for Physician-Scientists funded by the National Cancer Institute of Canada. Dr. Humphries is a Scholar of the Medical Research Council of Canada and Dr. C. Eaves is a Terry Fox Research Scientist of the National Cancer Institute of Canada.

\section{References}

1. Raskind, W. H., and P. J. Fialkow. 1987. The use of cell markers in the study of human hematopoietic neoplasia. Adv. Cancer Res. 49:127-167.

2. Prchal, J. F., J. W. Adamson, S. Murphy, L. Steinmann, and P. J. Fialkow. 1978. Polycythemia vera. The in vitro response of normal and abnormal stem cell lines to erythropoietin. J. Clin. Invest. 61:1044-1047.

3. Coulombel, L., D. K. Kalousek, C. J. Eaves, C. M. Gupta, and A. C. Eaves. 1983. Long-term marrow culture reveals chromosomally normal hematopoietic progenitor cells in patients with Philadelphia chromosome-positive chronic myelogenous leukemia. N. Engl. J. Med. 308:1493-1498.

4. Kalousek, D. K., C. J. Eaves, and A. C. Eaves. 1984. In vitro cytogenetic studies of haemopoietic malignancies. Cancer Surv. 3:439-463.

5. Vogelstein, B., E. R. Fearon, S. R. Hamilton, and A. P. Feinberg. 1985. Use of restriction fragment length polymorphisms to determine the clonal origin of human tumors. Science (Wash. DC). 227:642-645.

6. Gregory, C. J., and A. C. Eaves. 1977. Human marrow cells capable of erythropoietic differentiation in vitro. Definition of three erythroid colony responses. Blood. 49:855-864.

7. Krystal, G., C. J. Eaves, and A. C. Eaves. 1984. CM Affi-Gel Blue chromatography of human urine: a simple one-step procedure for obtaining erythropoietin suitable for in vitro erythropoietic progenitor assays. Br. J. Haematol. 58:533-546. 
8. Eaves, C. J., and A. C. Eaves. 1978. Erythropoietin (Ep) dose-response curves for three classes of erythroid progenitors in normal human marrow and in patients with polycythemia vera. Blood. 52:1196-1210.

9. Cashman, J., A. C. Eaves, and C. J. Eaves. 1985. Regulated proliferation of primitive hematopoietic progenitor cells in long-term human marrow cultures. Blood. 66:1002-1005.

10. Reed, K. C., and D. A. Mann. 1985. Rapid transfer of DNA from agarose gels to nylon membranes. Nucleic Acids Res. 13:72077221.

11. Vogelstein, B., E. R. Fearon, S. R. Hamilton, A. C. Preisinger, H. F. Willard, A. M. Michelson, A. D. Riggs, and S. H. Orkin. 1987. Clonal analysis using recombinant DNA probes from the X-chromosome. Cancer Res. 47:4806-4813.

12. Feinberg, A. P., and B. Vogelstein. 1983. A technique for radiolabeling DNA restriction endonuclease fragments to high specific activity. Anal. Biochem. 132:6-13.

13. Eaves A. C., and A. J. Eaves. 1984. Erythropoiesis in culture. Clin. Haematol. 132:371-391.

14. Murphy, S., H. Iland, D. Rosenthal, and J. Laszlo. 1986. Essential thrombocythemia: an interim report from the polycythemia vera study group. Semin. Hematol. 23:177-182.
15. Singer, J. W., P. J. Fialkow, L. Steinmann, V. Najfeld, S. J. Stein, and W. A. Robinson. 1979. Chronic myelocytic leukemia (CML). Failure to detect residual normal committed stem cells in vitro. Blood. 53:264-268.

16. Dubé, I. D., C. M. Gupta, D. K. Kalousek, C. J. Eaves, and A. C. Eaves. 1984. Cytogenetic studies of early myeloid progenitor compartments in $\mathrm{Ph}^{\prime}$-positive chronic myeloid leukaemia (CML). I. Persistence of $\mathrm{Ph}^{1}$-negative committed progenitors that are suppressed from differentiating in vivo. Br. J. Haematol. 56:633-644.

17. Goto, T., M. Nishikori, Z. Arlin, T. Gee, S. Kempin, J. Burchenal, A. Strife, D. Wisniewski, C. Lambek, C. Little, S. Jhanwar, R. Chaganti, and B. Clarkson. 1982. Growth characteristics of leukemic and normal hematopoietic cells in $\mathrm{Ph}^{1-+}$ chronic myelogenous leukemia and effects of intensive treatment. Blood. 59:793-808.

18. Talpaz, M., H. M. Kantarjian, K. B. McCredie, M: J. Keating, J. Trujillo, and J. U. Gutterman. 1987. Clinical investigation of human leukocyte interferon in chronic myelogenous leukemia. Blood. 69:1280-1288.

19. Imakawara, K., R. V. Anthony, M. Kazemi, R. K. Marohi, H. G. Polites, and R. M. Roberts. 1987. Interferon-like sequence of ovine trophoblast protein secreted by embryonic tropheetoderm. $\mathrm{Na}$ ture (Lond.). 330:377-379. 